\title{
A rare case of coexistence of metastasis from head and neck squamous cell carcinoma and tuberculosis within a neck lymph node
}

\author{
Danila Caroppo, Daniela Russo ${ }^{\dagger}$, Francesco Merolla ${ }^{*}$, Gennaro llardi ${ }^{\dagger}$, Marialaura Del Basso de Caro, \\ PierPaolo Di Lorenzo, Silvia Varricchio, Massimo Mascolo and Stefania Staibano
}

\begin{abstract}
Coexistence of metastasis from squamous cell carcinoma and tuberculosis within lymph nodes is rare. We report a case of 86 years old woman with a mass in the left laterocervical region. The patient had undergone excision of a poorly differentiated squamous cell carcinoma from the mucosa of the left cheek, a few months before. Histological examination of a mass of few fused lymph nodes, isolated from left laterocervical lymphadenectomy, showed metastatic squamous cell carcinoma with concomitant granulomatous inflammation. A diagnosis of tuberculosis associated with malignancy was posed. The suspect was confirmed by a positive anamnestic finding of a previous tuberculosis infection. The granulomatous reaction may be associated with many types of tumor, and can be found in the draining lymph nodes. The possibility that this reaction is also due to a tuberculosis infection should be kept in mind for elderly oncology patient.
\end{abstract}

Keywords: Tbc, Lymph node metastasis, OSCC

\section{Background}

An association between tuberculosis and cancer has been frequently described. Warthin reported two cases of tuberculosis and carcinoma of mammary glands, in 1899 [1], Kaplan et al. examined the frequency of the coexistence between different cancer types and tuberculosis in a retrospective study [2]. Coexistence, instead, of tuberculosis and metastatic carcinoma in lymph nodes is a rare event; few reports are present in the literature, mainly involving metastases from breast cancer. Herein we report a case of node metastasis from oral squamous cell carcinoma coexisting with an infective granulomatous reaction due to mycobacterium tuberculosis; we discuss clinical, histological and immunohistochemical findings.

\footnotetext{
* Correspondence: francesco.merolla@unina.it

${ }^{\dagger}$ Equal contributors

Department of Advanced Biomedical Sciences, University of Naples "Federico
} II", via S. Pansini 5, 80131 Naples, Italy

\section{Case presentation}

A 86-years-old woman, whose smoking habits are not known, noted, in September 2013, the appearance of a lesion on the left cheek mucosa. She was followed the department of Oral and Maxillofacial Surgery. e physical examination revealed the presence of an lesion, $2 \mathrm{~cm}$ of diameter, lightly painful on pith hard/elastic consistence. The histological picture of an incisional biopsy of the lesion, revealed a hyperaccumulation restricted to the retromandibular and eft parapharyngeal regions (SUV 17.4) (Fig. 1a and b). A left laterocervical lymphadenectomy was then performed, and the sample was sent to the institutional Pathology 

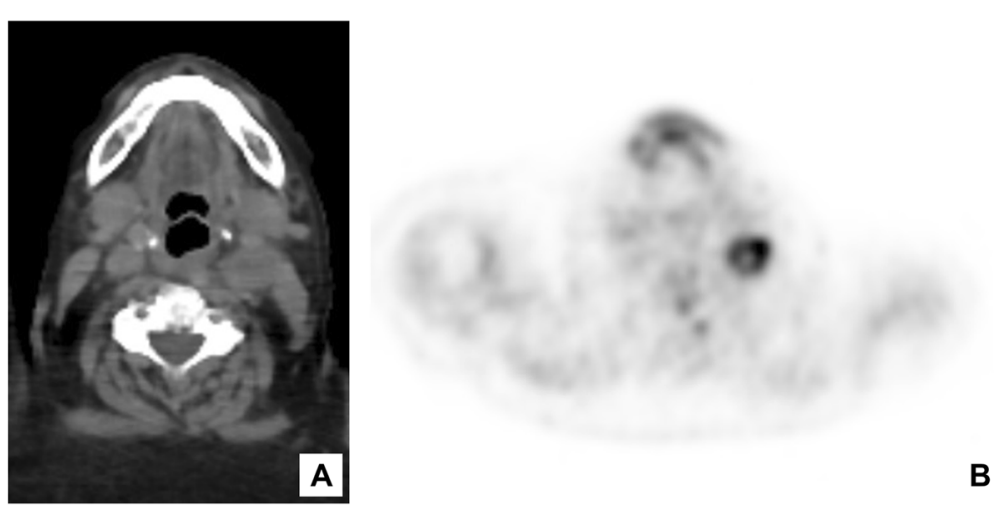

Fig. 1 PET-CT: a Axial CT image of the maxilla-facial region showing a left retromandibular mass. b PET image showing tracer hyperaccumulation at the retromandibular and left parapharyngeal regions

Unit. The surgical specimen was composed of a salivary gland, 12 single lymph nodes and a single mass of few fused lymph nodes (maximum diameter: $3 \mathrm{~cm}$ ). At microscopic examination, the lymph-node mass showed massive necrosis lined by granulomatous inflammation with palisading epithelioid and Langhans' giant histiocytes, in close association with metastatic sheets from a squamous cell carcinoma (Fig. 2a). The immunohistochemistry clearly evidenced the tumor nests (pan-cytokeratin positive) and the granulomatous reaction area (CD68 immunoreactive) (Fig. 2b and c). On the basis of morphological and immunohistochemical findings, we posed diagnosis of metastatic squamous cell carcinoma associated with necrotizing granuloma, strongly suggestive of mycobacterial infection/tuberculosis. Requestioning the patient about her previous pathological history, we finally found out that she had an episode of tuberculosis in the 1960s. The patient was redirected to the department of infectious diseases for further investigation; at $\mathrm{x}$-chest rays there was no evidence of pulmonary activity of the disease, as reported for most patients with tuberculosis of the head and neck lymph nodes [3].

Mycobacterium tuberculosis (MTB) infects one third of the world's population and is the second leading cause of death from an infectious disease after HIV. The association between cancer and tuberculosis infection was already described [1, 2, 4], some authors suggest that the onset of these chronic disease is favored by a state of immunosuppression. Lymphadenitis is the most frequent manifestation of extrapulmonary tuberculosis and neck swelling is the commonest presentation (multiple lymph node widening without constitutional signs). Some authors have reported the presence of tuberculous lymphadenitis in a patient with breast cancer [5] and in a patient with a history of sovraglottic carcinoma [6] who were misdiagnosed as malignant lymph node based on the imaging. Cancer can be associated with a granulomatous response in the draining lymph node [7]; in particular, squamous cell carcinoma can elicit this reaction, being tumor keratins the reaction target [8]. The simultaneous presence of tuberculosis infection and metastasis in the same lymph node is a rare event, described mostly in patients with breast cancer [9-11] and less in patient with a history of head and neck squamous cell carcinoma $[8,12]$. Here we describe an unexpected, rare case of node metastasis from oral squamous cell carcinoma coexisting with tuberculosis; to our knowledge, our case represents the first involving the oral cavity as the source of the primary tumor. Wang at al reported two cases of OSCC with node metastasis

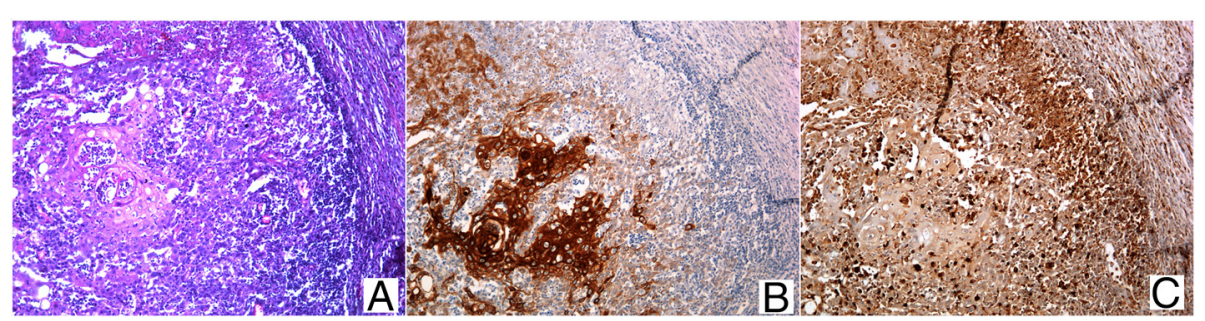

Fig. 2 Representative micrograph of the fused lymph nodes: H/E staining showing the granulomatous reaction, with palisading epithelioid histiocytes, and metastatic deposit (a); tumor nests are intensely positive to CK pan immunostaining (b); CD68 immunostaining confirms the presence of epithelioid histiocytes (c). (a, b, c magnification 100x) 
and TB infection, being the two pathological entities found separately in different lymph-nodes [13].

\section{Conclusions}

In case of node metastasis of head and neck squamous cell carcinoma, the possibility of TBC-lymphadenitis should always be considered even in non-endemic areas, particularly in elderly patients, mainly due to the cancerinduced immune suppression.

\section{Consent}

Written informed consent was obtained from the patient for publication of this case report and accompanying images. A copy of the written consent is available for review by the Editor-in Chief of this journal.

\section{Abbreviations}

HIV: human immunodeficiency virus; MTB: mycobacterium tuberculosis; OSCC: oral squamous cell carcinoma; PET: positron emission tomography; Tbc: tubercolosis; US: ultra sounds.

\section{Competing interests}

The authors declare that they have no competing interests.

\section{Authors' contributions}

DC participated in the case report design, execution, analysis and interpretation of data, and drafting the manuscript. DR, FM participated in interpretation of data, and assist in drafting the manuscript. SV, GI participated in execution of the immunohistochemical part of the case. SS, MM made the original diagnosis of the case, conceived of the study design, participated in data interpretation, and in drafting the manuscript. MDC, PDL critically reviewed the manuscript. All authors read and approved the final manuscript.

\section{Acknowledgements}

We thank Dr. Amanda Tedeschi for the English editing of the manuscript.

Received: 9 July 2015 Accepted: 17 October 2015

Published online: 29 October 2015

\section{References}

1. Warthin AS. The coexistence of tuberculosis and carcinoma of the mammary gland. Am J Med Sci. 1899;118:25.

2. Kaplan MH, Armstrong D, Rosen P. Tuberculosis complicating neoplastic disease: a review of 201 cases. Cancer. 1974;33:850-8.

3. Bruzgielewicz A, Rzepakowska A, Osuch-Wójcikewicz E, Niemczyk K, Chmielewski R. Tuberculosis of the head and neck - epidemiological and clinical presentation. Arch Med Sci. 2014;10(6):1160-6.

4. Khan AH, Sulaiman SA, Muttalif AR, Hassali MA, Khan TM. Tuberculous lymphadenitis at Penang General Hospital, Malaysia. Med Princ Pract. 2011;20(1):80-4.

5. Baslaim MM, Al-Amoudi SA, Al-Ghamdi MA, Ashour AS, Al-Numani TS. Case report: breast cancer associated with contralateral tuberculosis of axillary lymph nodes. World J Surg Oncol. 2013;11:43.

6. Yong DJ, Iskandar H, Razif MY. Tuberculous cervical lymphadenitis in a patient with suspected neck recurrence. Chin Med J (Engl). 2012;125(9):1667-8.

7. Bhatia A, Kumar Y, Kathpalia AS. Granulomatous inflammation in lymph nodes draining cancer: A coincidence or a significant association. Int J Med Med Sci. 2009;1(2):013-6.

8. Barwad A, Gowda KK, Dey P. Co-existent of tuberculosis and squamous cel carcinoma in a lymph node diagnosed by fine needle aspiration cytology. Cytopathology. 2012;23(4):276-7.

9. Pandey M, Abraham EK, Chandramohan K, Rajan B. Tuberculosis and metastatic carcinoma coexistence in axillary lymph node: a case report. World J Surg Oncol. 2003;1(1):3.
10. Avninder SP, Saxena S. Infiltrating ductal carcinoma of the breast, metastatic to axillary lymph nodes harboring primary tuberculous lymphadenitis. Pathol Oncol Res. 2006;12(3):188-9.

11. Salemis NS, Razou A. Coexistence of breast cancer metastases and tuberculosis in axillary lymph nodes-a rare association and review of the literature. Southeast Asian J Trop Med Public Health. 2010;41(3):608-13.

12. Gheriani H, Hafidh M, Smyth D, O'Dwyer T. Coexistent cervical tuberculosis and metastatic squamous cell carcinoma in a single lymph node group: a diagnostic dilemma. Ear Nose Throat J. 2006;85(6):397-9.

13. Wang WC, Chen JY, Chen YK, Lin LM. Tuberculosis of the head and neck: a review of 20 cases. Oral Surg Oral Med Oral Pathol Oral Radiol Endod. 2009;107(3):381-6.

\section{Submit your next manuscript to BioMed Central and take full advantage of:}

- Convenient online submission

- Thorough peer review

- No space constraints or color figure charges

- Immediate publication on acceptance

- Inclusion in PubMed, CAS, Scopus and Google Scholar

- Research which is freely available for redistribution 